\title{
Research on Language Economics and College English Education Zhihong Fan ${ }^{1, a}$ \\ ${ }^{1}$ Jiangxi University of Engineering, Xinyu, Jiangxi Province, 338000 \\ ${ }^{a}$ email,
}

Keywords: Research, Language Economics, College English Education

\begin{abstract}
College English education should follow the law of market economy, objectively and rationally understand the college English learning motivation, the economic value of the language and the economic benefits and the allocation of educational resources should accurately grasp the market demand, effectively develop the teacher knowledge resources improve the students' cognitive ability and autonomous learning ability. In the construction of the curriculum system we should pay attention to the combination of language knowledge and skills, through English to strengthen the cultural quality and interdisciplinary professional knowledge integration, improve the comprehensive competitiveness of students.
\end{abstract}

\section{Introduction}

The phenomenon of college English education is also a relatively common and lasting phenomenon. Thus, how should university English education follow the law of market economy? From the perspective of language economics, based on the value and utility, cost and benefit as the theoretical basis for the existing college English education in all aspects of the problems and analysis of the implementation of reform improve the utilization of teaching resources, in order to facilitate the cultivation of students' comprehensive and practical ability of foreign language.

\section{Analysis of College English Education}

It Cannot Meet the Needs of Diverse Student. In the perspective of language economics, English learning is actually an investment, how to improve the benefits of investment is the focus of the study of educators. Under modern society, society presents a diversified development trend and students' learning needs are also reflected in many aspects. The traditional English teaching to read and write and other basic knowledge of English as the core, a single boring content, many colleges and universities have continued such a teaching model, making the teaching effect is very poor.

A Large Number of Educational Resources Waste. At present, most colleges and universities to implement credit graduation system, but the English in this process accounted for significant high scores. In addition, teachers as an important educational resource, its role cannot be fully reflected in the college curriculum in the lack of rationality, the lack of professional English ability of students, basic knowledge is not comprehensive. English class is too long but the teaching task is not clear, a lot of time! Resources! Money is wasted, is not conducive to the improvement of English teaching efficiency.

It Cannot Get the Expected Income of English Teaching. English in the process of achieving the role of communication is more and more obvious, the community needs more and more English talent. The level of English proficiency of college students often determines the difference between their work and even the benefits of salary. However, in the setting of college English curriculum in our country, we neglected the cultivation of students' application ability and disintegrated with social reality. In addition to English students, most of the teaching content of a single, application is not strong, less concerned about the teaching methods, not targeted or even in the form.

\section{The Overview of Language Economics Theory}

Speaking of economics, people tend to say that it is the science of economic problems. In fact, 
economics is a way of thinking. To be precise about the science of rational choice is a way of knowing people's rational choice of behavior. This concept dictates that economic theory can be extended to other areas. Today's new science and technology applications, especially network technology bring a revolution, so that people can cross time constraints to achieve interactive multi-directional communication. Language is the key to ensuring that dialogue is smooth. Learning a foreign language may mean winning a new starting point in the world leading to the world. The study of the relationship between language and economy is attracting more and more attention.

The earliest emergence of linguistic economics was attributed to the American economist Marschak's 1965 issue in the Journal of Behavioral Science entitled "The Economics of Language". Later economists have continued to add that language economics is "with the information economics", "is the study of language and economic interrelationship" is "the use of the concept of economics and methods to study the relationship between language variants and language, especially with regard to those affected by economic changes."

On the basis of absorbing the research results of human capital theory and educational economics, language economics has further systematized and rationalized the relationship between language and economy through quantitative qualitative analysis. The main points can be summarized as follows:

First, the definition of language as a human capital is a pioneer of language economists. Language is the human capital that can be used to supplement and replace other types of capital, and is the instrumental capital of other human capital (knowledge and skills). The "capital" of language is the inevitable product of the economic age.

Second, learning a foreign language is an economic investment in human capital production. Part of the reason people learn foreign language is influenced by economic factors, that is, to consider the "investment costs" of learning foreign languages and "investment expected benefits" after learning language. Language skills that communicate in one or more foreign languages are seen by a growing number of people as a "gold capital" of high gold, because the expected return is high, so people are tired of investing in foreign language learning.

Thirdly, the economic value of the language is high and low, mainly depends on the language in a variety of tasks, various occupations and departments in the use of the degree of use, and the degree of use by the language of the rule of supply and control.

Fourth, the economic utility of language depends on many factors. This includes the urgency of the labor market, the number of applications in the market, consumer psychology, the frequency of interpersonal relationships and so on.

\section{The Enlightenment of Language Economics on College English Education}

Rational Understand the Motivation Tools of English Learning. Linguistics holds that motivation and purpose are influencing the important factors of learning. Intrinsic motivation comes from the learner's interest in a particular learning or learning task; external motivation comes from outside influences, for future work and life needs. All along, linguists believe that intrinsic motivation is more conducive to foreign language learning. Because the intrinsic motivation lasts longer, it is an important prerequisite for language learning to achieve long-term success.

According to the basic theory of language economics, this paper argues that the objective motivations after rational thinking and selection can also stimulate the establishment of long - term effective learning motivation and interest. The rational choice comes from self-introspection and economic expectations. "For our college students, English learning has both the external role of tools and the inherent role of self-identity." "Tools" is an obvious feature of English social function, but also the obvious characteristics of student learning motivation. The so-called instrumental external role, both the impact of social demand factors, but also is from the value of the economic considerations. Interest not only from the psychological and physiological emotional identity, but also can be in the economic market environment to cultivate.

Often with those who have the ability to apply English and hope that by strengthening the foreign language ability, access to excess economic income, enhance personal values, cast a greater 
achievement of students, have a strong learning motivation and passion. From the fundamental interests of people, co-ordinate the subjective and objective factors, taking into account the social and economic needs, the maximum, the greatest interest to seek development and promote development in order to achieve personal goals. This power is endless, never exhausted, it is inspired by the great enthusiasm is immeasurable. Therefore, as long as people objectively and scientifically understand a thing and a behavior behind the social and economic interests can fully mobilize the subjective initiative. Attention to the external motivation of foreign language learning, coordination of foreign language learning intrinsic motivation can really stimulate the enthusiasm of learning in order to truly achieve the sustainable development of college English learning positive and effective way.

Objectively Understand the Economic Value of Language. The economic value of the language of the specific performance: First, people can help with the language to complete a successful task, so as to obtain direct economic benefits. Second, in order to meet the potential social needs of the future talent market, actively reserve foreign language capacity resources, the expected future opportunities to win indirect economic benefits. Of course, the value of language must be based on the specific circumstances of socio-economic development, based on the theory of cost-benefit in language economics, dynamic adjustment timely changes. Analysis of these economic values of the language can enrich our understanding of language break through the traditional linguistic research model from the abstract from the psychology, complex sociology and other aspects of metaphysical interpretation, dissects into a realistic, real economic phenomena, revealing the interest-driven mechanism of subjective will of language learning.

Scientific Understand the Economic Benefits of College English Education. The economic benefits of college English education depend on the difference between the income and cost of college English learning. For individuals, English users may earn higher income in the future because of their language skills, paying the cost, the cost of learning English, and the opportunity cost of learning English. From the perspective of society as a whole, the economic benefits of college English learning are manifested in the transaction costs saved by college graduates in the international economic exchanges in China due to the use of English as an international language, or because of the opportunities and trade interests created by language communication the social and economic costs of college English education include the public expenditure incurred by the state for college English education, the cost of education for all individual learners, the waste of educational resources due to over-education and irrational educational structures and the investment of resources into foreign languages the social opportunity cost of education.

Theoretically, the macroeconomic benefits of college English education can be regarded as the sum of the economic benefits of all individuals who have received college English education. By analyzing the changes in total revenue and total cost increment, you can find the right way to maximize your profits. This method is called marginal analysis. Calculating and analyzing the changes in total income and total cost increment in English can help people get the right way to learn English to maximize their accomplishments.

Rationally Allocate Educational Resources. Economics argues that people have the desire and action to increase their own interests as much as possible in social activities. Maximizing the pursuit of efficiency is actually a process of rational trade-off comparison, "people in the face of choice, to achieve the objectives of the options are listed and can foresee the consequences of the implementation of these programs, on this basis, based on certain the value of the standard, select the most suitable for the realization of the target program "process.

The flow and integration of foreign language education resources should also follow such principles. Students and teachers as the human resources of education, financial and material resources in the existence of distinction and wait for the case, is bound to seek and select those who benefit to maximize their own interests to achieve the combination of resources. And has a high quality of financial, material and human resources supply side - the school, of course will provide education services to be selected in order to achieve its maximum economic and social benefits. In short, the realization of maximizing utility is the result of mutual selection of educational resources 
based on their own interests.

Such as education equipment, teachers, curriculum, teaching materials selection, practical training, etc., how to make full use of resources, how to highly reflect the value of human capital is placed in the current the preferred task.

The best benefit of the school is to cultivate excellent teachers and students, to create scientific and technological products and human resources, so as to benefit the society. The best benefit of teachers is the value-added and the ability to display their own academic value. The best benefit of students is professional knowledge and comprehensive quality the perfection and the success of social employment. All are around the "value" of this economic lever, the accumulation of value, improve the use of value, and then accumulated, and then increased, spiral rise. College English reform should also be based on the principle of interest to promote the value and the use of the value of a benign transformation, recognize the importance of scarce resources, rational choice, in line with the laws of the diversified development of the new road.

\section{Conclusion}

Language is actually a kind of human capital and economics believes that learning language is an economic investment. Especially for English learning, its position in the community is getting higher and higher, more and more widely used. Improve the practical ability of college students in English has become the focus of teaching, modern society, the requirements of talent is no longer simply grasp the basic knowledge of language can, but can be better applied. English teaching reform becomes inevitable, but the implementation process has always been slow to carry out, to the language teacher has brought a lot of confusion.

\section{References}

[1] Zhang Qianhui. Talk about the information age of college English education and media literacy education [J]. Campus English. 2017 (11)

[2] Huang Huiyan, Yang Yuanyuan. Successful intellectual theory and college English education reform [J]. Modern women (late). 2014 (12)

[3] Wang Congong. Problems and Countermeasures of College English Education [J]. Asia-Pacific Education. 2015 (09)

[4] Chen Liqin, Huang Lehui.Study on "Guiding Wisdom" in College English Education [J]. Statistics \& Management 2015 (07)

[5] Kuang Li. Modern university English education policy implementation potential problems and its solution strategy [J]. Snow lotus. 2015 (29)

[6] Li Wenjuan. College English education reform [J]. Encouragement inspirational. 2016 (17) 